University of Nebraska - Lincoln

DigitalCommons@University of Nebraska - Lincoln

CSE Journal Articles

Computer Science and Engineering, Department

$3-14-2020$

\title{
Validating a CS Attitudes Instrument
}

Ryan Bockmon

Stephen Cooper

Jonathan Gratch

Mohsen Dorodchi

Follow this and additional works at: https://digitalcommons.unl.edu/csearticles

This Article is brought to you for free and open access by the Computer Science and Engineering, Department of at DigitalCommons@University of Nebraska - Lincoln. It has been accepted for inclusion in CSE Journal Articles by an authorized administrator of DigitalCommons@University of Nebraska - Lincoln. 


\section{Validating a CS Attitudes Instrument}

\author{
Ryan Bockmon \\ University of Nebraska - Lincoln \\ Lincoln, Nebraska \\ rbockmon@cse.unl.edu \\ Jonathan Gratch \\ Texas Woman's University \\ Denton, Texas \\ jgratch@twu.edu.
}

\author{
Stephen Cooper \\ University of Nebraska - Lincoln \\ Lincoln, Nebraska \\ scooper22@unl.edu \\ Mohsen Dorodchi \\ University of North Carolina at Charlotte \\ Charlotte, North Carolina \\ mdorodch@uncc.edu
}

\begin{abstract}
This paper discusses the validation of a modified computer science attitudes instrument. Dorn and Tew's Computing Attitude Survey was modified by adding questions on gender issues and questions regarding students' perceptions of the utility of computing. Current trends indicate an increasing gap in the genders graduating with degrees in computer science. The new questions explore student attitudes and perceptions of women in computing while items related to computer science utility explore the importance of CS in students' lives and careers. These modifications necessitated the re-validation of the new revised instrument and comparison of the results obtained with in the original instrument by Dorn and Tew.
\end{abstract}

\section{KEYWORDS}

Assessment; Validity; Replication; Gender

\section{ACM Reference Format:}

Ryan Bockmon, Stephen Cooper, Jonathan Gratch, and Mohsen Dorodchi. 2020. Validating a CS Attitudes Instrument. In The 51st ACM Technical Symposium on Computer Science Education (SIGCSE'20), March 11-14, 2020, Portland, OR, USA. ACM, New York, NY, USA, 6 pages. https://doi.org/10. $1145 / 3328778.3366830$

\section{INTRODUCTION}

Included as one of the five challenges in Sahami's article on more inclusive computing [17], computer science researchers need to promote computing education research to be a more accepted research field. Sahami pointed out that in order to achieve this goal, computing education research needs "benchmarks that can consistently and objectively be measured to make studies more comparable and show progress in the field". This paper discusses the validation of a modified computer science attitudes instrument as an attempt to establish a stepping stone towards such benchmarks on student attitudes to be used for computing education research.

Permission to make digital or hard copies of all or part of this work for personal or classroom use is granted without fee provided that copies are not made or distributed for profit or commercial advantage and that copies bear this notice and the full citation on the first page. Copyrights for components of this work owned by others than the author(s) must be honored. Abstracting with credit is permitted. To copy otherwise, or republish, to post on servers or to redistribute to lists, requires prior specific permission and/or a fee. Request permissions from permissions@acm.org.

SIGCSE '20, March 11-14, 2020, Portland, OR, USA

(C) 2020 Copyright held by the owner/author(s). Publication rights licensed to the Association for Computing Machinery.

ACM ISBN 978-1-4503-6793-6/20/03 _\$15.00

https://doi.org/10.1145/3328778.3366830
Student attitudes towards computing are important factors related to students' success in learning computing [26]. Previous research points to important attitudes including "confidence, interest, usefulness, and professional[ism]" [11] and "self-efficacy, attitudes toward computers, and desirability of learning computing skills" [26]. Students with poor self-efficacy often struggle more in computing courses [4]. Gender differences can shape or exasperate attitudes toward computing [18], while successful experiences in computing for pre-college and college students also shape student success in computing $[5,24]$.

The percentage of females graduating with a bachelor's degree in computer science reached its peak in 1984 at $37.1 \%$. A decade later the female graduation rate dropped by $10 \%$ and by 2012 only $18 \%$ graduates with a bachelor's degree in computer science were women[1,21]. As the gender gap further increases we need a better understanding of why it is happening. To do so, we need to start by asking the right questions about students' perceptions of women and role of gender in computing.

This paper details our experiences modifying and revalidating a computing attitudes instrument. In modifying an already validated instrument one must reestablish validity and reliability. Validity is the extent to which an instrument measures what it is supposed to measure and performs as it is designed to perform, while reliability is the idea of, does the instrument consistently measure what it is intended to measure? [2].

\subsection{CS Attitudes Surveys}

Ramalingam and Wiedenbeck $[15,16]$ created and validated the Computer Programming Self-Efficacy Scale in 1998. Their goal was to create and validate an instrument that examined students' self-efficacy and confidence about their own ability to learn how to program. The instrument was written primarily in regard to $\mathrm{C}++$ programming language, as $\mathrm{C}++$ was the most widely used programming language taught in introductory CS courses at the time. Exploratory Factor analysis (EFA) was conducted on the 32 questions and indicated 4 factors (independence and persistence, complex programming tasks, self-regulation and simple programming tasks).

Wiebe et al. [23] created a computer science attitudes instrument derived from the Fennema-Sherman mathematics attitudes scales [9], modified to reflect programming and computer science rather than mathematics. It consists of 57 questions on self-confidence, motivation, attitudes toward success, females in CS, and usefulness 
of CS. Despite an initial study, the validity of this instrument was never fully established.

Hoegh and Moskal [12] created another computer science attitudes survey that measures undergraduate student perceptions of computer science who were enrolled in Calculus II, a first year required mathematics course for all students. This allowed the population to represent first year students across the entire institution. The initial survey started with 52 question and 5 pre-defined factors on confidence, interest, gender, usefulness, and professionalism.

Dorn and Tew [7] developed the Computing Attitudes Survey (CAS), an extension of the Colorado Learning Attitudes about Science Survey (CLASS) [3]. The researchers identified 4 differences in the design of the CAS instrument compared to the others discussed above. First, the CAS statements are designed to elicit attitudes about knowledge and problem solving in the CS discipline. Second, the CAS statements are written to measure attitudes about CS more generally and not restricted to attitudes about a specific course, pedagogy or programming language. Third, the CAS items have been selected and tested to provide clear and concise statements with a single interpretation. Fourth, the CAS establishes categories of attitudes and sub scales on the survey based on an empirical analysis of the student responses themselves, rather than determining categories upfront based on the researchers' areas of interest.

The CAS was revised four times from 2011-2015. The first version was created by adapting the original questions of the CLASS to a more computing-focus survey. Version 2 was based on thinkaloud interviews with faculty and students which were piloted during the fall of 2011 with 447 introductory students [22]. The second version, CASv2, consisted of 53-Likert type questions, which resulted in 8 factors found during an EFA. These were problem solving - transfer, problem solving - strategies, problem solving - fixed mindset, real world connections, problem solving - confidence, problem solving - sense making, abstraction and personal interest/enjoyment. These were further revised in version three (CASv3) which was administered as a pre-post format over three semesters across two universities with a total number of 2873 survey responses. The researchers ran an EFA on CASv3 revealing 7 latent factors. A confirmatory factor analysis (CFA) was run on each of the 7 factors, and the survey was then revised again based on the results of the CFA. The latest version, CASv4, has 26 questions and five factors: problem solving - transfer, personal interest, problem solving - strategies, real-world connections, and problem solving fixed mindset [7].

\section{COMPUTING ATTITUDES DESIGN}

Dorn and Tew's CASv4 consists of 26 questions, using a 5-point Likert scale. To their survey, we added a subset of 9 questions from Wiebe et al.'s survey [23] representing a range of attitudes relating to gender issues. We note that these questions have a possibility of introducing stereotype threat $[19,20]$. An additional five questions were added probing students' attitudes towards the utility of computing. Cooper et al.'s [6] study noticed that their student attitudes survey did not fully capture the results from individual interviews, particularly of Latinas, about the importance of student views concerning gender equality issues and the utility of computing. All added questions also used a 5-point Likert scale.
With permission from Dorn and Tew, CASv4 was modified by adding questions focusing on students perceptions concerning the utility of computing and on their thoughts about gender issues. As the instrument CASv4 was modified, it was necessary to establish the new instrument's reliability.

\section{METHODS}

Data was collected in a pre-post format in introductory computing classes across three universities; University of Nebraska - Lincoln, University of North Carolina, and Texas Woman's University, during the spring, summer and fall of 2018. All student participation was voluntary, with incentives used to encourage students to participate. The instruments were available for students to take online during the first 3 weeks of class as a pre-test and offered during the final 3 weeks as a post-test. A total of 827 students took the modified CS attitudes survey ( 585 males, 232 females and 10 students who did not identify themselves as either male or female).

\section{ANALYSIS}

Factor analysis was used to determine underlying factors that might be in the survey item design. An EFA was conducted on all questions and used calculations of Ordinal $\alpha$ to test reliability of the modified version of the CASv4 [10]. An acceptable minimum value of .70 is considered acceptable for an Ordinal $\alpha$ in educational research [14]. The broad purpose of factor analysis is to summarize data so that relationships and patterns can be easily interpreted and understood [25]. More technically, a factor analysis is a data reduction technique that takes a collection of observed random variables and groups them into common factors based on their correlation patterns.

Eigenvalues are used to determine how many factors to retain. The eigenvalue for a given factor measures the variance in all the questions. Eigenvalues are calculated by summing the squares of all the loading values for a given factor. If a factor has a low eigenvalue, it is contributing little to the explanation of variance in the factor. Kaiser's rule suggests retaining all factors that are above the eigenvalue of 1 [13]. Other ways of determining when to remove a factor is when it contains less than three questions or when it consists of many complex loading values, e.g. questions that are associated with more than one factor (cross-loading) [25].

After establishing factors, we investigated the correlations between the factors using a correlation matrix and a Pearson correlation coefficient, to determine the strength of the correlation between each of the factors.

\section{RESULTS}

\subsection{Exploratory Factor Analysis}

A factor analysis was conducted on the modified CASv4 and the results were compared to the results Dorn and Tew obtained.

The original CASv4 contained 5 factors: Problem Solving - Transfer, Personal Interest, Problem Solving - Strategies, Real-World Connections, and Problem Solving - Fixed Mindset [7]. Scoring high in the Personal Interest factor suggests a student has a higher interest in computing. Scoring high in Problem Solving - Strategies suggests a student considers him/herself to have strong problemsolving strategies when it comes to CS. Scoring high in Real-World Connections suggests a student has a strong relationship between 
Table 1: Pattern Matrix

\begin{tabular}{|c|c|c|c|c|c|c|c|}
\hline & \multicolumn{7}{|c|}{ Factors } \\
\hline & & 1 & 2 & 3 & 4 & 5 & 6 \\
\hline DT & Q20 & .768 & & & & & \\
\hline DT & Q24 & .685 & & & & & \\
\hline DT & Q15 & .640 & & & & & \\
\hline DT & $\widetilde{\mathrm{Q}} 2$ & .565 & & & & & \\
\hline DT & Q23 & .561 & & & & & \\
\hline DT & Q6 & .552 & & & & & \\
\hline DT & Q21 & .516 & & & & & \\
\hline DT & Q3 & .464 & & & & & \\
\hline DT & $\widetilde{Q} 25$ & .444 & & & & & \\
\hline DT & Q18 & .432 & & & & & \\
\hline DT & Q22 & .399 & & & & & \\
\hline DT & Q1 & .355 & & & & & -.326 \\
\hline $\mathrm{W}$ & Q28 & & .976 & & & & \\
\hline W & Q29 & & .918 & & & & \\
\hline $\mathrm{W}$ & Q27 & & .858 & & & & \\
\hline W & Q30 & & .843 & & & & \\
\hline W & Q35 & & .667 & & & & \\
\hline $\mathrm{W}$ & Q31 & & -.349 & & & .334 & \\
\hline $\mathrm{N}$ & Q38 & & & .931 & & & \\
\hline $\mathrm{N}$ & Q37 & & & .929 & & & \\
\hline $\mathrm{N}$ & Q36 & & & .924 & & & \\
\hline DT & $\widetilde{Q} 26$ & & & .745 & & & \\
\hline DT & Q10 & & & & .643 & & \\
\hline DT & Q16 & & & & .599 & & \\
\hline DT & Q5 & & & & .561 & & \\
\hline DT & Q17 & & & & .547 & & \\
\hline DT & Q12 & & & & .483 & & \\
\hline DT & Q7 & & & & .452 & & \\
\hline DT & Q8 & & & & .426 & & \\
\hline DT & Q9 & & & & .374 & & \\
\hline W & Q32 & & & & & .694 & \\
\hline $\mathrm{W}$ & Q34 & & & & & .588 & \\
\hline W & Q33 & & & & & .511 & \\
\hline DT & $\mathrm{Q} 4$ & & & & & & .697 \\
\hline DT & Q13 & & & .408 & & & .564 \\
\hline DT & Q11 & & & & & & .425 \\
\hline
\end{tabular}

relating CS concepts to the real world. Scoring high in the Problem Solving - Fixed Mindset factor suggests a student has a narrower mindset when it comes to CS concepts. Scoring high in Problem Solving - Transfer suggests a student has a lower ability to see or apply connections between ideas and concepts.

An EFA was performed on the modified instrument (Principal Axis Factory and a Promax rotation) yielding seven factors with eigenvalues greater than 1 . The total number of factors were further reduced to 6 by removing factors with multiple loadings or having fewer than three questions associated with the factor. Table 1 displays the pattern matrix of each factor and the loading values of each question. (Any loading value with absolute value less than .32 is depicted as blank.) Table 4 in the appendix shows the wording of each question.

\subsection{Factor Breakdown}

Factor 1, named Problem Solving - Fixed Mindset, has a eigenvalue of 10.35 , accounting for $26.6 \%$ of the variance. It contains 12 questions $(20,24,15,2,23,6,21,3,25,18,22$ and 1). Question 1 has a negative loading value on factor 6 but a positive loading value on factor 1, so we removed it from factor 6 and kept it in factor 1 . Factor 1 contains all questions found in both Dorn and Tew's factor Problem Solving - Fixed Mindset and Problem Solving - Transfer [7].

Factor 2, named Gender Equity, has an eigenvalue of 4.61, accounting for $11.8 \%$ of the variance. It consists of 5 questions (28, $29,27,30$ and 35). Question 31 had a negative loading value with factor 2 and a positive loading value with factor 5 , so we removed it from factor 2 and kept it in factor 5. All questions are from Wiebe's original study [23]. All questions in this factor explore students' opinions concerning the equity between males and females in CS.

Factor 3, named Importance, had an eigenvalue of 2.63, accounting for $6.75 \%$ of the variance. It consists of 4 questions $(38,37,36$ and 26). Question 26 was the only questions that was in Dorn and Tew's original work [7]. All questions in this factor highlights the importance of computing in one's life and the desire to learn more about computation.

Factor 4, named Problem Solving - Strategies (as in Dorn and Tew's work) has an eigenvalue of 1.9 , accounting for $4.88 \%$ of the variance. It consists of 8 questions; 10, 16, 5, 17, 12, 7, 8 and 9. It was consistent with the CASv4 factor of Problem Solving - Strategies questions plus 3 extra questions from CASv4 Real-World Connections. Our factor consists of slightly different questions from the original Problem Solving - Strategies found in Dorn and Tew's work [7]. We believe that our factor captures the same concept as the original Problem Solving - Strategies within our data set. We decided that it was appropriate to keep the factor name the same.

Factor 5, named Gender Bias, has an eigenvalue of a 1.33 accounting for $3.4 \%$ of the variance. It consists of 4 questions $(31,32,34$, and 33) exploring gender biases towards females in CS; All question are from Wiebe's original study [23].

Factor 6, was named Personal Interest, has an eigenvalue of 1 accounting for $2.58 \%$ of the variance and consists of 3 questions (4, 13 and 11). Question 13 had both a positive loading value on both factor 3 and factor 6 . As it had a higher loading value on factor 6 (.564 vs . 408), we decided to keep it in factor 6 . Our factor 6 consisted of 3 out of the 4 questions originally found in Dorn and Tew's Personal Interest factor. We decided that it was appropriate to keep the factor name the same.

\subsection{Reliability}

The reliability of the factors found in our data set and the reliability of Dorn and Tew's original factors were compared in Table 2. Column 1 shows the reliabilities (as Ordinal $\alpha$ ) calculated for the factors Dorn and Tew found in their study [7]. The reliabilities of all but one factor found in Dorn and Tew's study had similar reliability in our data set (column 2). Real-World Connections had 
Table 2: CASv4 Factor Reliabilities

\begin{tabular}{lccc}
\hline Factor & $\begin{array}{c}\text { Original } \\
(\text { Ordinal } \alpha)\end{array}$ & $\begin{array}{c}\text { Original w/ our data } \\
(\text { Ordinal } \alpha)\end{array}$ & $\begin{array}{c}\text { Our Factors } \\
(\text { Ordinal } \alpha)\end{array}$ \\
\hline Problem Solving - Fixed Mindset & .90 & .83 & .88 \\
Gender Equity & N/A & N/A & .96 \\
Importance & N/A & N/A & .95 \\
Problem Solving - Strategies & .80 & .78 & .82 \\
Gender Bias & N/A & N/A & .85 \\
Personal Interest & .90 & .87 & .84 \\
Problem Solving - Transfer & .71 & .74 & N/A \\
Real-World Connections & .90 & .77 & N/A \\
\hline
\end{tabular}

Table 3: Correlation Matrix

\begin{tabular}{|c|c|c|c|c|c|c|}
\hline Factors & $\begin{array}{l}\text { Problem Solving } \\
\text { Fixed Mindset }\end{array}$ & Gender Equity & Importance & $\begin{array}{c}\text { Problem Solving } \\
\text { Strategies }\end{array}$ & Gender Bias & $\begin{array}{c}\text { Personal } \\
\text { Interest }\end{array}$ \\
\hline Problem Solving - Fixed Mindset & 1.00 & $-.399^{*}$ & $-.488^{*}$ & $-.480^{*}$ & $.565^{*}$ & $-.469^{*}$ \\
\hline Gender Equity & $-.399^{*}$ & 1.00 & $.266^{*}$ & $.205^{*}$ & $-.662^{*}$ & .024 \\
\hline Importance & $-.484^{*}$ & $.266^{*}$ & 1.00 & $.625^{*}$ & $-.167^{*}$ & $.608^{*}$ \\
\hline Problem Solving - Strategies & $-.480^{*}$ & $.205^{*}$ & $.625^{*}$ & 1.00 & $-.167^{*}$ & $.733^{*}$ \\
\hline Gender Bias & $.565^{*}$ & $-.662^{*}$ & $-.278^{*}$ & $-.167^{*}$ & 1.00 & $-.117^{*}$ \\
\hline Personal Interest & $-.469^{*}$ & 0.24 & $.608^{*}$ & $.733^{*}$ & $-.117^{*}$ & 1.00 \\
\hline
\end{tabular}

*significant correlation at the 0.01 level

the highest decrease in reliability $(.90->.77)$ and this could explain why it did not show up in our EFA. Both factors that were found from Wiebe's survey, Gender Equity and Gender Bias, had high reliability. Gender Equity has an Ordinal $\alpha$ of .96, and Gender Bias has an Ordinal $\alpha$ of .85. The Importance factor, that was mostly comprised of our added questions, also had a high reliability with an Ordinal $\alpha$ of .95 .

\subsection{Factor Correlations}

We calculated a correlation matrix (Table 3 ) to determine correlations among the factors themselves. Calculating a Pearson's Correlation Coefficient using Evan's suggested scale can determine the strength of the correlations. Evan suggests that a Pearson's Correlation Coefficient between 0.0 and .19 is considered very weak, 0.2 0.39 is weak, $0.4-0.59$ is moderate. $0.6-0.79$ is strong, and $.80-1.0$ is very strong [8].

The Problem Solving - Fixed Mindset factor has a moderate negative correlation with the Importance factor $(\mathrm{r}=-.488)$, the Problem Solving - Strategies factor $(r=-.480)$, and the Personal Interest factor $(\mathrm{r}=-.469)$, a moderate positive correlation with the Gender Bias factor $(r=.565)$ and a weak negative correlation with the and the Gender Equity factor $(r=-.399)$. The Gender Equity factor has a strong negative correlation with the Gender Bias factor $(\mathrm{r}=-.662)$ and a weak negative correlation with the Problem Solving - Fixed Mindset factor $(r=-.399)$. The Importance factor has a strong positive correlations to both the Problem Solving - Strategies factor $(\mathrm{r}=.625)$ and Personal Interest factor $(\mathrm{r}=.608)$ and a moderate negative correlation to Problem Solving - Fixed Mindset factor $(\mathrm{r}=-.484)$. The Problem Solving - Strategies factor has a strong positive correlation with the Personal Interest factor $(\mathrm{r}=.733)$ and a moderate negative correlation with the Problem Solving - Fixed Mindset factor $(r=-.-480)$. The Gender Bias has a moderate positive correlation with the Problem Solving - Fixed Mindset factor $(r=.565)$ and a strong negative correlation with the Gender Equity factor $(\mathrm{r}=-$-.662). The Personal Interest factor has a strong correlation with both the Problem Solving - Strategies factor $(r=.733)$ and the Importance factor $(r=.608)$ and a moderate negative correlation with the Problem Solving - Fixed Mindset factor $(r=-.469)$.

Two out of the three original factors have similar correlations to what Dorn and Tew found in their study. Our Personal Interest and Problem Solving - Strategies factors have a strong correlation of 0.733 while Dorn and Tew also had a strong correlation of 0.78 . Problem Solving - Strategies and Problem Solving - Fixed Mindset have a moderate correlation of 0.480 while Dorn and Tew also had a moderate correlation of 0.56. Personal interest and Problem Solving - Fixed Mindset have a weak correlation of 0.469 , while Dorn and Tew had a strong correlation of a 0.63 .

\section{DISCUSSION}

Similar results to Dorn and Tew [7] were obtained. Like Dorn and Tew, we found the Personal Interest factor to have a strong positive correlation with the Problem Solving - Strategies factor suggesting that introductory computing students who have strong problemsolving strategies show more interest in CS. We found a negative correlation with both the Personal Interest factor and the Problem Solving - Strategies factor to the Problem Solving - Fixed Mindset factor, suggesting students who score higher in problem solving 
strategies are more open minded and have a higher ability to transfer ideas and concepts.

Adding the 9 extra questions from Wiebe's survey [23] resulted in two new factors, Gender Equity and Gender Bias. The Gender Equity and the Gender Bias factors produced a strong negative correlation $(\mathrm{r}=-.662)$ suggesting they are the opposite of each other. Gender Bias factor also had a moderate positive corelation with the Problem Solving - Fixed Mindset factor suggesting that introductory computing students who have a strong bias towards males in computer science have more of a fixed mindset when trying to solve problems.

There is a positive correlation between the Personal Interest, the Problems Solving - Strategies, and the Importance factors. This suggests that for students who have a higher interest in computation, computation is more important in their lives, and they have developed higher problem-solving skills when working on computation.

\section{LIMITATIONS}

Several factors could have impacted the validity of our research. The first factor is that our survey data was collected on a combination of both pre- and post-tests while Dorn and Tew collected data over several semesters and ran their factor analysis on only post-test data $[7,22]$. It is unclear whether the inclusion of both pre- and post-test data within the factor analysis impacted the emerging factors. We will continue collecting data using the modified instrument and conduct exploratory and confirmatory factor analysis to determine if the constructs remain stable.

The second factor is that the questions targeting students' attitudes towards females in computing could imposed stereotype treat $[19,20]$. It is unclear whether stereotype treat exists in our study, but moving forward we will work to create questions that equally ask students' attitude towards both male and female. Hopefully reducing any chance that stereo type treat is imposed by our survey.

\section{CONCLUSION}

The development of the modified computer science attitude survey incorporated items on CS utility, women, and gender bias to the CASv4 producing a new instrument that built upon the strengths of CASv4. The EFA conducted on the modified survey resulted in 6 factors: Problem Solving - Fixed Mindset, Gender Equity, Importance, Problem Solving - Strategies, Gender Bias and Personal Interest.

All six factors tested above the .70 Ordinal $\alpha$ and account for $56 \%$ of the overall variance. While three new factors (Gender Equity, Gender Bias and Importance) were produced, two of the original factors found in Dorn and Tew's work (Problem Solving - transfer and Real World Connections) [7] were not preserved. This is not surprising based on the inclusion of new items in the survey.

With continuing measurement of the validity and reliability of this new CS attitude survey, it is our hope to inform CS educators and researchers to better understand the attitudes and perceptions of CS students and use the information to guide the design of more inclusive, real world problem based CS instruction, reduce gender bias, promote equality, and increase and retain women entering the field.

\section{ACKNOWLEDGEMENT}

This material is based upon work partially supported by the $\mathrm{Na}-$ tional Science Foundation under Grant Numbers 1711780, 1711830, and 1712331. Any opinions, findings, and conclusions or recommendations expressed in this material are those of the author(s) and do not necessarily reflect the views of the National Science Foundation.

\section{REFERENCES}

[1] [n. d.]. Chart of the Day: The declining female share of computer science degrees from $28 \%$ to $18 \%$. http://www.aei.org/publication/chart-of-the-day-the-decliningfemale-share-of-computer-science-degrees-from-28-to-18. ([n. d.]). Accessed: June 1, 2019.

[2] [n. d.]. Instrument, Validity, Reliability. https://researchrundowns.com/ quantitative-methods/instrument-validity-reliability/. ([n. d.]). Accessed: Jan 1, 2019.

[3] W. K. Adams, K. K. Perkins K. K., M. Dubson, N. D Finkelstein, and C. E. Wieman. 2005. The design and validation of the Colorado Learning Attitudes about Science Survey. AIP Conference Proceedings 790, 1 (2005), 45-48. AIP.

[4] T. Busch. 1995. Gender differences in self-efficacy and attitudes towards computers. Fournal of Educational Computing Research 12, 2 (1995), 147-158.

[5] C. Comber, A. Colley, D.J. Hargreaves, and L. Dorn. 1997. The effects of age, gender and computer experience upon computer attitudes. Educational Research 39, 2 (1997), 123-133.

[6] S. Cooper, K. Wang, I. Maya, and S. Sorby. 2015. Spatial skill training in introductory computing. ICER ' 15 (2015), 13-20.

[7] B. Dorn and A. Tew. 2015. Empirical validation and application of the computing attitudes survey. Computer Science Education 25, 1 (2015), 1-36.

[8] J. Evans. 1996. Straightforward statistics for the behavioral sciences. Mathematics.

[9] E. Fennema and J. A. Sherman. 1976. Fennema-Sherman mathematics attitudes scales. Instruments designed to measure attitudes toward the learning of mathematics by females and males. fournal for research in Mathematics Education 7, 5 (1976), 324-326.

[10] Guhn M. Gadermann, A. and D. Zumbo. 2012. Estimating ordianl reiability for Likert-type and ordinal item response data: A conceptual, empirical, and practical guide. Practical Assessment, Research Evaluation 17, 3 (2012).

[11] D. Heersink and B. Moskal. 2010. Measuring high school students' attitudes toward computing. SIGCSE '10 (2010), 446-450.

[12] A. Hoegh and B.M. Moskal. 2009. Examining science and engineering students' attitudes toward computer science. FIE '09 (2009), W1G-1-W1G-6. IEEE.

[13] H. Kaiser. 1960. The application of electronic computers to factor analysis. Educational and Psychological Measurement 20, 1 (1960), 141-151.

[14] C. Lance, M. Butts, and L. Michels. 2006. The sources of four commonly reported cutoff criteria: What did they really say? Organizational Research Methods 9, 2 (2006), 202-220.

[15] V. Ramalingam, D. LaBelle, and S. Wiedenbeck. 2004. Self-efficacy and mental models in learning to program. ACM SIGCSE Bulletin 36, 3 (2004), 171-175.

[16] V. Ramalingam and S. Wiedenbeck. 1998. Development and validation of scores on a computer programming self-efficacy scale and group analyses of novice programmer self-efficacy. Journal of Educational Computing Research 19, 4 (1998), 367-381.

[17] M. Sahami. 2018. Paving a Path to More Inclusive Computing. ACM Inroads 9, 4 (Nov. 2018), 85-88. https://doi.org/10.1145/3230700

[18] L. Shashaani. 1997. Gender differences in computer attitudes and use among college students. Fournal of Educational Computing Research 16, 1 (1997), 37-51.

[19] Steele C. M. Spencer, S. J. and D. M. Quinn. 1999. Stereotype threat and women's math performance. Journal of experimental social psychology 35, 1 (1999), 4-28.

[20] C. M. Steele. 1997. A threat in the air: How stereotypes shape intellectual identity and performance. American psychologist 52, 6 (1997), 613.

[21] Camp T. 2001. Women in computer sciences: reversing the trend. (2001).

[22] A. Tew, B. Dorn, and O. Schneider. 2012. Toward a validated computing attitudes survey. ICER '12 (2012), 135-142.

[23] E. N. Wiebe, L. Williams, K. Yang, and C. Miller. 2003. Computer science attitude survey. Technical Report NCSU CSC TR-2003-1 (2003).

[24] B.C. Wilson. 2002. A study of factors promoting success in computer science including gender differences. Computer Science Education 12, 1-2 (2002), 141-164.

[25] A. Yong and S. Pearce. 2013. A beginner's guide to factor analysis: Focusing on exploratory factor analysis. Tutorials in quantitative methods for psychology 9,2 (2013), 79-94.

[26] Y. Zhang and S. Espinoza. 1988. Relationships among computer self-efficacy, attitudes toward computers, and desirability of learning computing skills. fournal of Research on Computing in Education 30, 4 (1988), 420-436. 
Table 4: Attitude Survey Questions

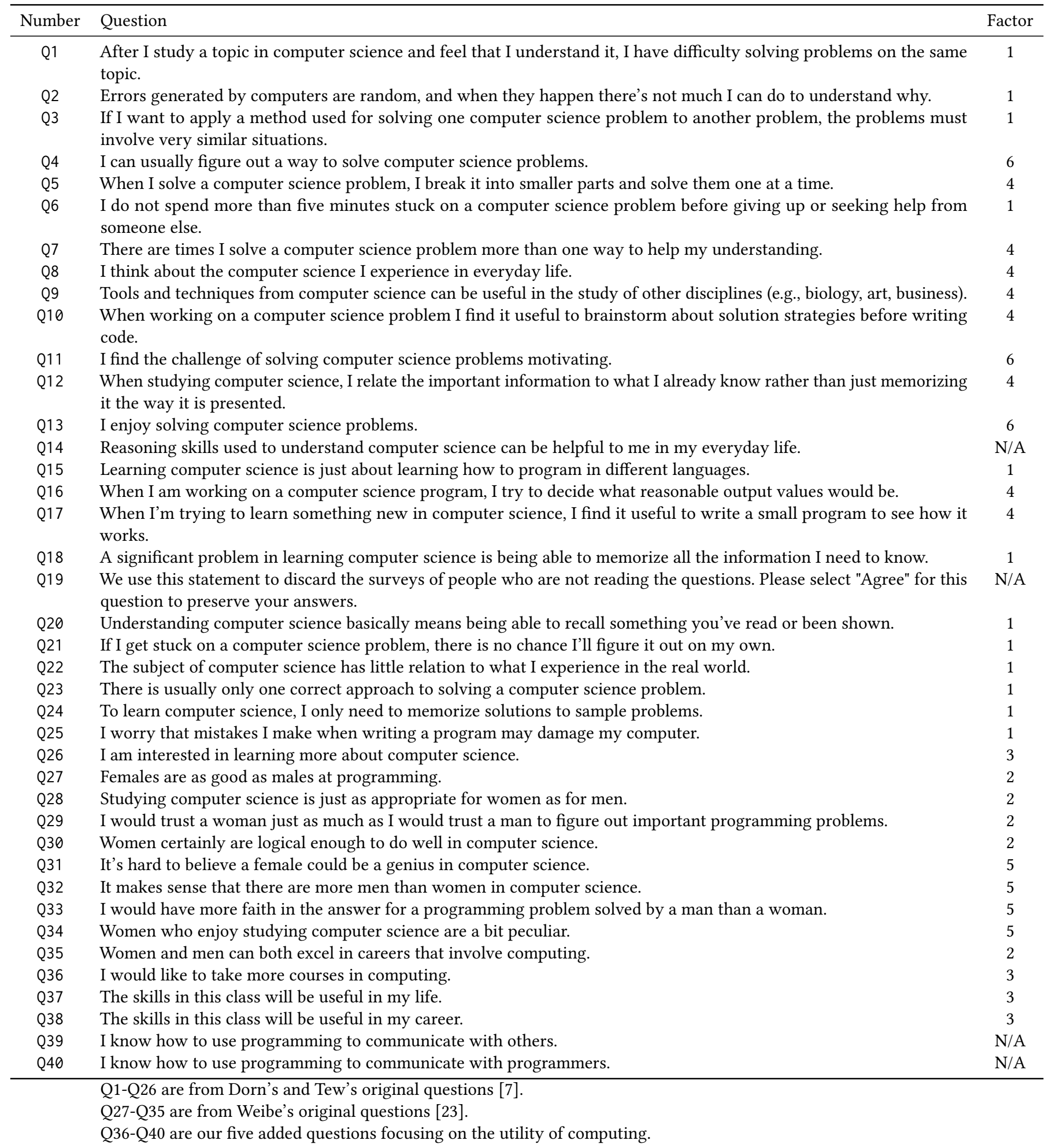

